\title{
Which Image Types do Universities Tweet?
}

Emma Stuart, Mike Thelwall, David Stuart. Statistical Cybermetrics Research Group, University of Wolverhampton, WV1 1LY, UK

emma.stuartewlv.ac.uk, m.thelwall@wlv.ac.uk, dp stuartehotmail.com

Direct comments to: emma.stuart@wlv.ac.uk

About the author: Emma is a postdoctoral researcher at the University of Wolverhampton who specializes in social media content analysis.

Universities use social media to attract prospective staff, students, and funding; to engage with current students; and to support teaching and learning. Images on social media are becoming particularly dominant, and whilst Twitter is not primarily an image-based social media service, nonetheless 36 percent of links shared on Twitter point to an image. This research paper compares the types of images that universities post on Twitter to the results of previous research that has investigated the types of images that universities post on Instagram, in order to better understand how universities are using the two services for image sharing

The most popular type of image tweeted by universities was showcasing (61 percent), followed by humanizing images (20.9 percent). The dominance of showcasing images on Twitter fits with the notion of Twitter as an information source rather than a networking source, with it predominantly being used as a means of 
one-way communication with current students to broadcast university-specific information, rather than for attracting prospective staff, students, and funding, or to support teaching and learning.

\section{Introduction}

Many universities have social media profiles for different purposes. These include using them as branding tools to showcase what the university has to offer in an attempt to attract prospective staff, students, and funding (Kittle and Ciba, 1999; Rolfe, 2003); engaging with current students (Hansen et al., 2012; Salomon, 2013); and supporting teaching and learning (Moran et al., 2011; Salomon, 2013). Social media services that are predominantly image-based, such as Instagram and Snapchat, are increasingly popular because the social media image is the 'dominant visual form of the 2010s' (Hochman, 2014). Nevertheless, although most UK and US universities (Parr, 2014) had a Twitter account by 2013, most UK universities did not have an Instagram account by 2016 (Stuart et al., 2017). Twitter is not primarily image-based, but can be used to share images, including from other sites (Thelwall et al., 2016). For universities, images can help to add interest to social media streams (Burkhardt, 2010), which may be why by 2013, 36 percent of links shared on Twitter were found to point to an image (Bennett, 2013). It is important to assess the types of images tweeted by universities to understand their communication strategies and to help them maximise the effectiveness of their Twitter profiles. The results of this 
investigation are also compared to the results of a previous study of Instagram (Stuart et al., 2017) in order to understand how strategies differ between the two platforms.

Understanding the similarities and differences in how universities post images across different social media platforms will provide better insights into the roles that different social media platforms provide for a university's online communication strategy (e.g., Which platforms are better for using images to share important university information? Which platforms use images most effectively as a conduit for engagement with followers?).

\section{Literature review}

\section{Twitter in universities}

With the reduction in government support and the introduction of tuition fees in the UK, universities now have to compete more proactively against each other to increase enrolment (Stamp, 2004). More resources are now being spent on branding so that universities can attempt to distinguish themselves from one another (Rolfe, 2003). Branding phrases such as, 'the best', 'world class', and 'leading' institution (Bélanger et al., 2002) are often used in marketing materials, and unsurprisingly, a university's website is seen as a key branding tool (Opoku et al., 2006). Research by Duarte et al. (2010) however highlights that factors related to education aren't the only ones that a university should focus on in order to successfully differentiate themselves from other institutions. Jenkins (1991) advocates the 
need for visual identity in order for a university to market itself, and Westcott Alessandri (2001) adds that logos, taglines, colour palette, facilities, former students, and a university's public behaviour are all elements that contribute towards a university's visual identity and image.

Over recent years students have come to expect that the universities they attend will make use of various different social media platforms as they 'know nothing other than a life with the internet' (Selwyn, 2012), and therefore participation in social media is now necessary for a university to engage with its environment and present its visual identity (Peranginangin and Alamsyah, 2015). Bélanger et al. (2014) found that there was three times more activity on Twitter than Facebook in a sample of 106 Canadian universities, and approximately 36\% of universities were found to have 'very active' Twitter usage. Constantinides and Zinck Stagno (2011) also highlight that the global reach of social media makes it a perfect avenue for institutional branding. A literature review by Conole and Alevizou (2010) of the use of web 2.0 tools in higher education reveals that Twitter in particular is used predominantly for:

- Broadcasting. Opinion sharing and distribution or dispersal of information, self-promotion and campaigning, public relations and marketing

- Opinion sharing about events, sharing of ideas, information and commentary 
- Backchannels at conferences or events (audience channels, serendipity/types of review and reflection)

- Crowd-sourcing of news and evidence from the ground

- Surveying and gathering opinion.

In a poll of 224 community colleges in the USA, Davis III et al. (2012) found that Twitter was used 'to inform students about upcoming events and activities, athletic games and competitions, deadlines, reminders, general college announcements, school closings due to inclement weather or other reasons, alerts, and emergencies', and that it was used as a one-way communication tool. Marketing, branding, and recruitment was the second most popular use. In a survey of 148 colleges and universities in the United States, Canada, Australia and New Zealand, Reuben (2008) found that for those institutions that use Twitter, 50 percent of them say it is updated by their marketing/communications/ and public relations office, with 50 percent reporting that they use it to communicate with current students, and the other 50 percent to target information at alumni. Others have advocated that Twitter can be an invaluable tool during emergency situations in academic institutions (Swartzfager, 2007). However, research by Linvill et al. (2012) revealed that 89\% of Twitter posts from a sample of 1130 tweets covering 113 US universities and colleges were directed towards the general public rather than current students.

There is a body of work that examines the use of Twitter and 
social media in general from a teaching and learning perspective (Moran et al., 2011; Salomon, 2013), and Gruzd, Paulin et al. (2016) advocate for the use of Twitter in distance learning programmes. In a survey of 333 teachers, Gruzd, Haythornthwaite et al. (2016) found that Twitter was reported as being the second most popular social media tool used for teaching, with blogs/Wordpress coming first. As well as the formal reasons for universities using Twitter, it is also used in informal ways by the students themselves in order to supplement their learning experience (Dahlstrom et al., 2013). However, this investigation is not concerned with the use of Twitter by individual teachers or lecturers in order to support teaching and learning, and is more concerned with official front-facing university Twitter accounts that members of the general public are also able to see. There are limited research papers that have investigated universities' use of Twitter from this perspective.

\section{Uses of Twitter}

Twitter is a free microblogging platform that allows users to post short messages (Yoon and Chung, 2013), with 500 million tweets being posted each day by January 2017 (Omnicore, 2017). As of January 2019, the UK had 13.6 million active Twitter users (Statista, 2019), with 25 - 34 year olds being the most popular age bracket (accounting for 25.2\% of users) (Statista, 2018).

Twitter is used for many different reasons, including: keeping in touch with friends and colleagues (Zhao and Rosson, 2009); 
supporting informal communication at work (Zhao and Rosson, 2009); collaboration (Honeycutt and Herring, 2009); sharing interesting topics (Zhao and Rosson, 2009; Yoon and Chung, 2013); promoting an organisation's activities or business (Yoon and Chung, 2013); enhancing cyberspace presence (McFedries, 2007); gathering useful information for professional or personal interests (Zhao and Rosson, 2009; Yoon and Chung, 2013); asserting personal opinions or thoughts (Yoon and Chung, 2013); releasing personal stress (Zhao and Rosson, 2009); and seeking help and opinions from others (Zhao and Rosson, 2009; Yoon and Chung, 2013). Twitter users were originally limited to 140 characters per tweet, however, this was increased to 280 characters in November 2017 for all languages apart from Japanese, Korean, and Chinese (Rosen, 2017). These languages have dense writing systems, which allows them to say more in fewer characters.

Twitter users can follow other Twitter accounts to see the tweets posted by them (Kwak et al., 2010). Users can share tweets to their followers by retweeting them and retweet counts are sometimes used as a measure of a tweet's popularity. Users can also 'like' tweets, and tweets that are liked appear in the timelines of those users that follow the account in question. Hashtags (the \# symbol followed by a keyword) are used as usergenerated tags in Twitter (Chang, 2010). Hashtags group tweets together that are similar in terms of content, theme, intention, or context, making them more easily searchable (Tekulve and Kelly, $2013)$. 
Chung and Yoon (2013) claim that overall, Twitter is more of an information sharing network than a social network, with most tweets sharing information, opinion, and news. This is supported by Kwak et al. (2010), who claim that Twitter is an information source rather than a social networking site since 67.6 percent of users (out of 42 million studied) are not followed by any of the users that they themselves follow. Whilst Twitter's egalitarian information sharing capabilities is a positive attribute, the obvious general lack of expert oversight means that it is also vulnerable to the spread of inaccurate and fake news, rumours, and misinformation (Shao et al., 2016). This is a particularly important issue in a university setting, with any tweets containing misinformation having potentially detrimental effects on a large number of students. However, as most official university Twitter accounts are the responsibility of marketing/communications/public relation departments, it seems unlikely that misinformation would be deliberately tweeted. It could however be the case that misinformation was unknowingly distributed, in which case the university would need to take action to deal with the consequences of such a mistake.

\section{Images on Twitter}

Native photo sharing was introduced on Twitter in 2011. Before this, Twitter users who wanted to share images had to use thirdparty services like Twitpic and Yfrog. These images were not viewable in users' timelines but instead appeared as clickable 
links (Taylor, 2011). However, images can now be posted to Twitter via the Twitter smartphone app, the web, via SMS (Twitter Help Centre, no date), and directly from other social media services.

Twitter is widely used for image sharing (Thelwall et al., 2016) and has supported the rise of citizen journalism, aided by the fact that most Twitter users can share information virtually instantaneously on their mobile phones from wherever they happen to be (Murthy, 2011). In 2009, for example, an ordinary user's tweet was the first to broadcast an image of US Airways flight 1549 after a successful emergency landing in the Hudson River. The user had 170 followers on Twitter, but his photograph went viral and was seen around the world (Zdanowicz, 2014).

In an analysis of over two million tweets, Rogers (2014) found that incorporating images with tweets fostered a higher level of engagement among followers, with a 35 percent increase in retweets. Posts containing images have also been found to contain more intense emotion, and more positive emotion than posts containing only text, whereas in contrast, text is used more to express sarcasm and negative emotions (Bourlai and Herring, 2014).

Many studies have investigated the types of images posted to Twitter. Thelwall et al. (2016) conducted a content analysis on a random sample of 800 Twitter images from the UK and USA that were posted during one week. Images were classified with four facets: image format; image content; image purpose; and image time. 
Although most images were photographs, there were also phone screenshots, pictures of text messages, cartoons, collages, and a small number of professional images. In terms of the image content, just under a quarter of the images analysed were of an individual person, and this was closely followed by images of small groups of people (17 percent). Images of text - or where text was an important component of the image (e.g., an overlaid caption) - represented just under a third of the sample. Around 15 percent of the images were of famous people or related to them in some way. However, the purpose for posting an image was rarely clear (Thelwall et al., 2016).

In contrast, Chung and Yoon (2013) conducted a content analysis of 555 tweets that included images relating to the Boston bombings in 2013, focussing on why the images had been posted. Seven image purposes were found: illustration (a means of representing what is being described); emotive/persuasive (stimulating or conveying emotion or persuasion); aesthetic value (simply for aesthetic purposes or enjoyment); information processing (the use of data contained within the image); information dissemination (a piece of information); learning (gaining knowledge from the image); and generation of ideas (a means of provoking thought patterns or an inspirational means). The most common apparent motivations were to disseminate information, followed by emotive/persuasive reasons. Images intended to disseminate information tended to accompany tweets that were classified as information sharing and reporting news', and emotive images tended to accompany tweets that were 
expressing opinions (Chung and Yoon, 2013). Studies have also found that the type of content posted on social media services can have a positive impact on the number of comments, likes, and shares a post receives (Kim et al., 2015; Rauschnabel et al., 2012; Stuart et al., 2017), and Coelho et al. (2016) specifically found that on Instagram and Facebook, posts relating to events and promotion led to greater involvement from followers.

\section{Twitter vs Instagram}

Whilst Twitter is a microblogging service that has been appropriated for many uses, Instagram is primarily a social networking service for sharing images and videos. Users can take pictures, apply filters to change the look and feel of their images, and share those images with other followers (Stuart et al., 2017). Lee at al. (2015) found five primary motives for using Instagram: social interaction, archiving, self-expression, escapism, and peeking. Overall, Instagram seems to focus more on the aesthetics of individual images, whereas images on Twitter tend to supplement or complement the text of a tweet. Nevertheless, Instagram images typically originate from smartphones and tend to document users' lives rather than being separate artworks (Marwick, 2015). In contrast, images on Twitter typically originate from a more diverse range of sources. Approximately 9 percent of images tweeted from the UK and USA in one study contained text, such as chat dialogue or sayings, and another approximately 15 percent of the images were screen grabs 
from phones to share what the users were currently doing on their phone (e.g., listening to music, playing games, reading text messages, checking social media services, or looking at the weather) (Thelwall et al., 2016). Screenshots have been described as a virtual form of photography (Moore, 2014).

In 2016 Instagram's user base overtook that of Twitter, with Instagram having 500 million active users in 2016 (Lee, 2016), and Twitter still only having 326 million global active users in 2019 (Statista, 2019). Large companies (e.g., Adidas and Starbucks) are also able to get more engagement from followers on Instagram (3 percent) compared to Twitter (0.07 percent) (O'Reilly, 2014). A few images on Instagram are 'regrams', meaning images that were originally posted by someone else that a user has shared with their followers. Regrams in Instagram perform the same function as retweets in Twitter.

Following other users is unidirectional in both Twitter and Instagram, meaning that permission is not needed to follow either an Instagram or Twitter account (unless the person has set their account to private), and there is no expectation for reciprocal following (Marwick, 2015). Hashtags are also used similarly on both sites.

In 2012 (the same year that Instagram was bought by Facebook) Instagram disabled the ability for Instagram images posted to Twitter to be able to display properly in Twitter feeds (Bilton, 
2012). A link is now provided for users to click on instead, directing them to Instagram, although there are workarounds to this problem using the 'If This Then That' service (Calore, 2013). This move illustrates the competition between Instagram/Facebook and Twitter for image sharing, and Instagram specifically wants users to visit Instagram when viewing Instagram images.

An investigation into UK universities on Instagram found that at the time of data analysis (in the Spring of 2015) they had a limited presence. For general university accounts, humanizing images were the most frequent type of image (i.e., images with aspects of human character and elements of warmth/humour/amusement) (Stuart et al., 2017).

\section{Research questions}

This paper investigates how UK universities are using Twitter for image sharing. The following research questions are addressed as a starting point for an analysis of Twitter in comparison to Instagram.

RQ 1 - What types of images do universities post most frequently on Twitter?

Post type is seen as an important factor in determining interaction with viewers (Coelho et al., 2016; Kim et al., 2015; Rauschnabel et al., 2012; Stuart et al., 2017) 
RQ 2 - Is there a relationship between the type of image posted and the number of retweets it receives?

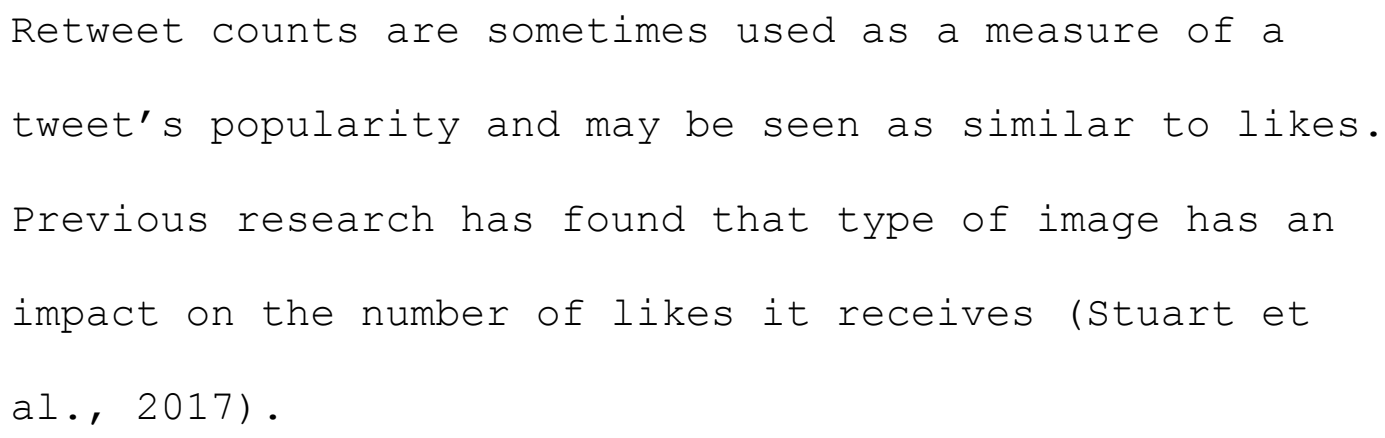

RQ 3 - Do universities post more images to Twitter than Instagram?

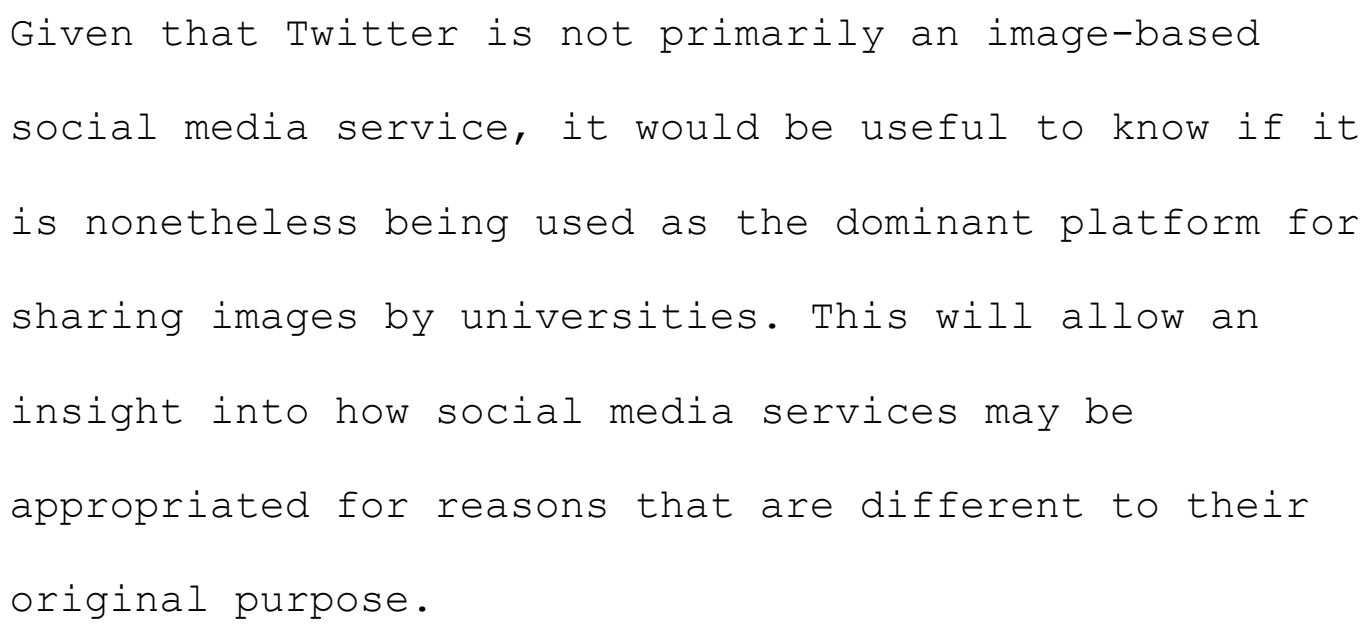

\section{Methodology}

\section{Identifying universities to investigate}

This investigation uses 51 UK universities previously analysed for Instagram (Stuart et al., 2017) in order to get comparable results. This list originated from a Times Higher Education Supplement table of 128 UK academic institutions with multiple units of assessment in the 2014 Research Excellence Framework $(\mathrm{REF})$, but was restricted to the 51 for which an official Instagram account could be found. The current Twitter study 
therefore concerns the parallel Twitter strategies of UK universities with an Instagram account.

\section{Data collection}

Tweets were collected on $28^{\text {th }}$ November 2015 using the free software Mozdeh (Thelwall, 2009) to query the public Twitter Application Programming Interface (API) for the 51 universities included in this investigation. The software gathers the latest tweets from each Twitter account, up to a maximum of approximately 2300 tweets. Using a site's API is a much more ethical way to collect data from a site in comparison to web scraping tools, and APIs are also a more efficient way of interacting with web servers. All of the images were then downloaded from those tweets that included them. This covered different time periods for the tweets (and images) because universities that were prolific Twitter users could generate 2300 tweets in a few months, whereas for other universities the 2300 tweets spanned several years. To overcome this, the raw Twitter data was compared with the Instagram data from the comparator study (Stuart et al., 2017) and images from outside the date range overlap were rejected.

From the date-filtered set of Twitter images, a random sample of 20 for each university was selected for inclusion in the final sample using Excel's random number generator. The same random sample method was used in the Instagram study (Stuart et al., 2017), and so the results are directly comparable in terms of 
universities, time periods and image selection mechanism. The final sample included 1,020 images.

\section{Analysis}

\section{Content analysis of images}

Images are inherently difficult to analyse due to their subjective nature and the fact that the same image may mean different things to different people, indeed even the same image may mean different things to the same person at different times (Graham, 2001). Content analysis is a rigorous and objective quantitative methodology that is well suited to manually analysing large numbers of images found online, which ultimately allows for the discovery of patterns (Rose, 2016). In order to conduct a content analysis of images, a coding scheme needs to be developed that is comprised of categories that are exhaustive, exclusive, and enlightening, and the categories 'must depend on a theorised connection between the image and the broader cultural context in which its meaning is made.' (Rose, 2016)

The content analysis scheme for use with Instagram images developed by stuart et al. (2017) was re-used in this investigation to ensure comparibility. Their scheme was based on a coding scheme developed by McNely (2012) for Instagram use in organisations. McNely (2012) investigated how three organisations (a prominent news organisation, a global non-profit organisation, and an online retailer) were shaping their external image via Instagram, using six types of image (1. Orienting; 2. Humanizing; 
3. Interacting; 4. Placemaking; 5. Showcasing; 6. Crowdsourcing). His content analysis scheme provided a good fit for university image posts on Instagram, and based on stuart et al's. (2017) rewording of McNely's (2012) categories for Instagram, the categories were re-worded again slightly so that they could also be used to investigate images posted to Twitter by university accounts (see Table 1 for final category wording and example images). Three things need to be taken into consideration when deciding what category an image should be assigned to: the content of the photo; the photo description and tags; and any interaction generated by the photo (McNely, 2012). The photo description and tags, and interaction generated by the photo relates to Rose's (2016) point that the category an image is assigned to depends on the connection between the image and its broader cultural context. Other research has also argued that accompanying text is important to give context to the overall meaning of an image (Angus and Thelwall, 2010; Bourlai and Herring, 2014).

In this investigation images were viewed alongside the tweet that accompanied them, as without the accompanying tweet, the image in isolation is likely to be analysed in a different way. For example, in Table 1, the example of a 'crowdsourcing' image that is given is that of a cat. Without the tweet that accompanies this image, there would be no way of knowing that the cat is actually the university's resident cat which has gone missing, and tweet is asking for people to get in touch if they have any information on the cats whereabouts. Without the accompanying tweet, the image 
could be mistakenly categorised as a 'humanizing' image, as this category description includes images that may be of animals or pets.

\section{Reliability of the content analysis scheme}

A second classifier coded 10 percent of the sample of 1,020 images to test the reliability of the content analysis scheme. Intercoder reliability for each of the six content analysis categories was measured using Krippendorf's alpha. Krippendorf (2004) suggests that tentative conclusions can be drawn from alpha scores between .667 and .8 . It was found that the agreement rates between the primary researcher and second classifier for three out of the six content analysis categories was not above .667 (Humanizing, 0.48; Interacting, 0.22; Showcasing, 0.55). The primary researcher and second classifier then discussed the results from the 10 percent sample, finding that two issues caused the low agreement rates. The first issue was the interpretation of the primary purpose of an image. Whilst an image may include an element of humour (and therefore could be classed as a humanizing image), if the image was nonetheless intended to showcase an element of the university in question, then this primary purpose would take precedence in the classification process (and the image should be classed as showcasing). The second issue was related to the crowdsourcing classification category. This category is for images posted to generate feedback, interaction, and engagement with viewers/followers. The second classifier perceived this to include offline interactions (e.g., encouraging followers to attend an 
event), whereas the primary researcher used this category to relate only to online interactions (e.g., completing a survey, giving comments/feedback on a question or query). Based on these discussions, the content analysis scheme was then reworded slightly to reduce these ambiguities (see Table 1). The primary researcher and second classifier then coded a further 10 percent of the sample of images, and the combined alpha score for the six coding categories subsequently reached .673, thus above the .667 threshold advised by Krippendorf. The first author then proceeded to code the remainder of the 1020 sample of Twitter images.

Table 1. Content analysis scheme for images posted to university Twitter accounts.

\begin{tabular}{|c|c|}
\hline Category and Description & Example tweet \\
\hline $\begin{array}{l}1 \text { - Orienting } \\
\text { - The primary focus of the image is of specific and unique } \\
\text { university (and university associated) locations, landmarks, } \\
\text { or artefacts (e.g., buildings/public areas/statues/university } \\
\text { affiliated objects). } \\
\text { - If the image is accompanied by a comment, description, or } \\
\text { hashtag(s) that specifically denote the exact name of the } \\
\text { building, statue, or location etc. then this image should be } \\
\text { classified as orienting. }\end{array}$ & 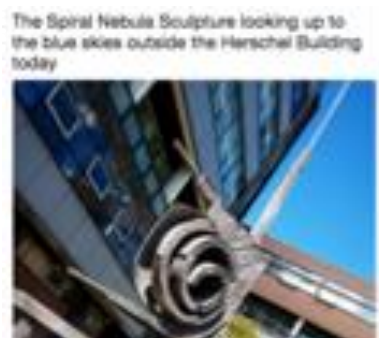 \\
\hline $\begin{array}{l}\text { 2 - Humanizing } \\
\text { - The primary focus of the image is of things that add more of } \\
\text { a human character or element of warmth/humour/or amusement to } \\
\text { the university's identity (e.g., close-up people shots } \\
\text { featuring staff, students, people affiliated with the } \\
\text { university, or university mascots). } \\
\text { - Retweets of student graduation photos where there is a close- } \\
\text { up of a particular student or a small group of students who } \\
\text { are all known to each other. } \\
\text { - Nature images may also be classified as humanizing if they } \\
\text { are not accompanied with a specific location title or } \\
\text { hashtag(s). }\end{array}$ & Hentint \\
\hline
\end{tabular}




\section{3 - Interacting}

- The primary focus of the image is centered around people interacting at university (and university associated) events rather than people merely posing for a staged photograph (e.g., an image of students participating in the freshers fair/an image of a group of people being shown around at a university open day/or an image of people actively participating in a sporting event).

\section{4 - Placemaking}

- The primary focus of the image is concerned with the university 'placing' their identity within locations or events (e.g., generic photos of the inside of buildings/lecture theatres/student halls, or generic images of graduation ceremonies where no one specific person is the focus of the image).

- Placemaking images will not be accompanied by specific comments, descriptions or hashtag(s) indicating the exact name of any buildings etc. contained within the image.

\section{5 - Showcasing}

- The primary focus of the image is to:

- Display products or goods for sale (e.g., university sweatshirts or merchandise)

- Showcase students' or staff work (e.g., close-up shots of artwork at an exhibition or other student work at a university event.

- If the image has been posted to display the 'winning image' in a photo competition of some sort

- If the image is of someone giving a lecture or talk as part of a specific event rather than just a normal student lecture

- If the image seeks to promote university specific services or advertise upcoming events (e.g., a photo of a poster advertising an upcoming public lecture, fundraising event, or charity ball)

- If the image is posted with the intention of encouraging people to attend an event in real-time (e.g., 'come on down to the fresher's fayre')

- Showcasing student achievements (e.g., students who have 'done well' or gone on to attain a good job or career).

- If the image seeks to report on generic student activities and events that have happened in the past (e.g., students taking part in a course field trip, or team squad lineup images).

- Images relating to 'best uni of the year' etc.

- Promotional images to advertise courses etc.

\section{6 - Crowdsourcing}

- The primary purpose of the image is that it has been posted with the intention of generating feedback, interaction, engagement, and online interaction with viewers/followers (e.g., an image of a new logo design asking followers for their thoughts and feedback; encouraging viewers to take part in a competition; asking viewers to complete an online survey).

- If the content of the image itself fits within a different classification category but the image is accompanied by text that explicitly asks for viewer feedback then this image should be classified as crowdsourcing.

Our nesidert eat Sple has been masins ince Saturday nigte Contact if you towe ance saturday nigt: Co

01245424300

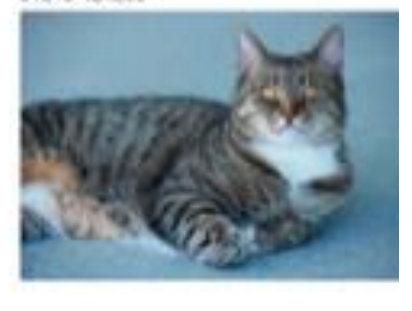

Multinominal logistic regression was used to answer RQ 2 . 


\section{Results}

A total of 33,484 images were downloaded from the latest approximately 2,300 tweets from each of the 51 universities. The mean average number of images per university account on Twitter was 204, compared to 97 on Instagram for the same period. For ease of comparison, the results of the previous Instagram study (Stuart et al., 2017) are included in the results tables below (see Table 2) .

\section{Content analysis of images}

Based on the content analysis of the 1,020 images from the 51 UK universities, most images tweeted were showcasing (61 percent). Most showcasing images promoted a university event, such as an open day or an upcoming talk, or proclaimed university achievements (Figure 1). Humanizing images (20.9 percent) were also common.

Table 2. Image types for 1020 random images from 51 UK university Twitter and Instagram accounts.

\begin{tabular}{|l|c|c|}
\hline \multicolumn{1}{|c|}{ Type of image } & $\%$ of Twitter images & $\%$ of Instagram \\
& & images \\
\hline 1. Orienting & $4.8 \%$ & $14.3 \circ$ \\
\hline 2. Humanizing & $20.9 \%$ & $31.0 \%$ \\
\hline
\end{tabular}




\begin{tabular}{|l|c|c|}
\hline 3. Interacting & $2.1 \%$ & $5.7 \%$ \\
\hline 4. Placemaking & $2.7 \%$ & $12.8 \%$ \\
\hline 5. Showcasing & $61.0 \%$ & $28.8 \%$ \\
\hline 6. Crowdsourcing & $7.7 \%$ & $7.5 \%$ \\
\hline
\end{tabular}
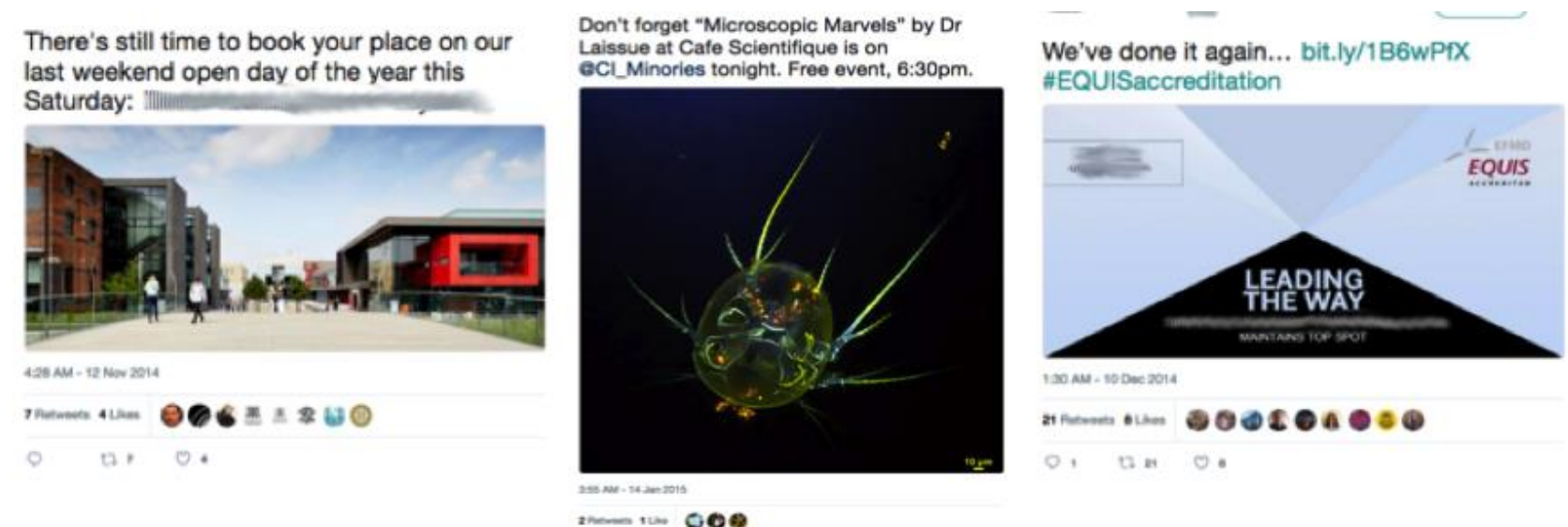

Figure 1. Examples of showcasing images.

\section{Type of image and number of retweets}

The most retweets for an image was 60 with an average of 2.7 , and 41.8 percent having no retweets. Multinomial regression was used to detect any relationship between image type and retweet counts. Due to the skew in the data for the number of retweets (i.e., a long right tail), a log transformation was used. This is necessary because multinomial logistic regression does not work on skewed data (Dancey and Reidy, 2004). Multinomial logistic regression found a statistically significant difference (p value 0.010) between the number of retweets that showcasing images received compared to humanizing images. For every 1 extra retweet that an image received, it was 1.7 times more likely to be a showcasing 
image. Thus, showcasing images were retweeted more than humanizing images.

\section{Do universities post more images on Twitter or Instagram?}

For each university, the number of images posted to Twitter was compared with the number of images posted to Instagram during the same time period. As mentioned in the methods section, the time periods were matched with the previous investigation (Stuart et al., 2017) to get comparable data. The Twitter accounts included 7,583 images compared to 3,615 images from the Instagram accounts for the same period (Figure 2). Despite this, some universities posted more to Instagram.

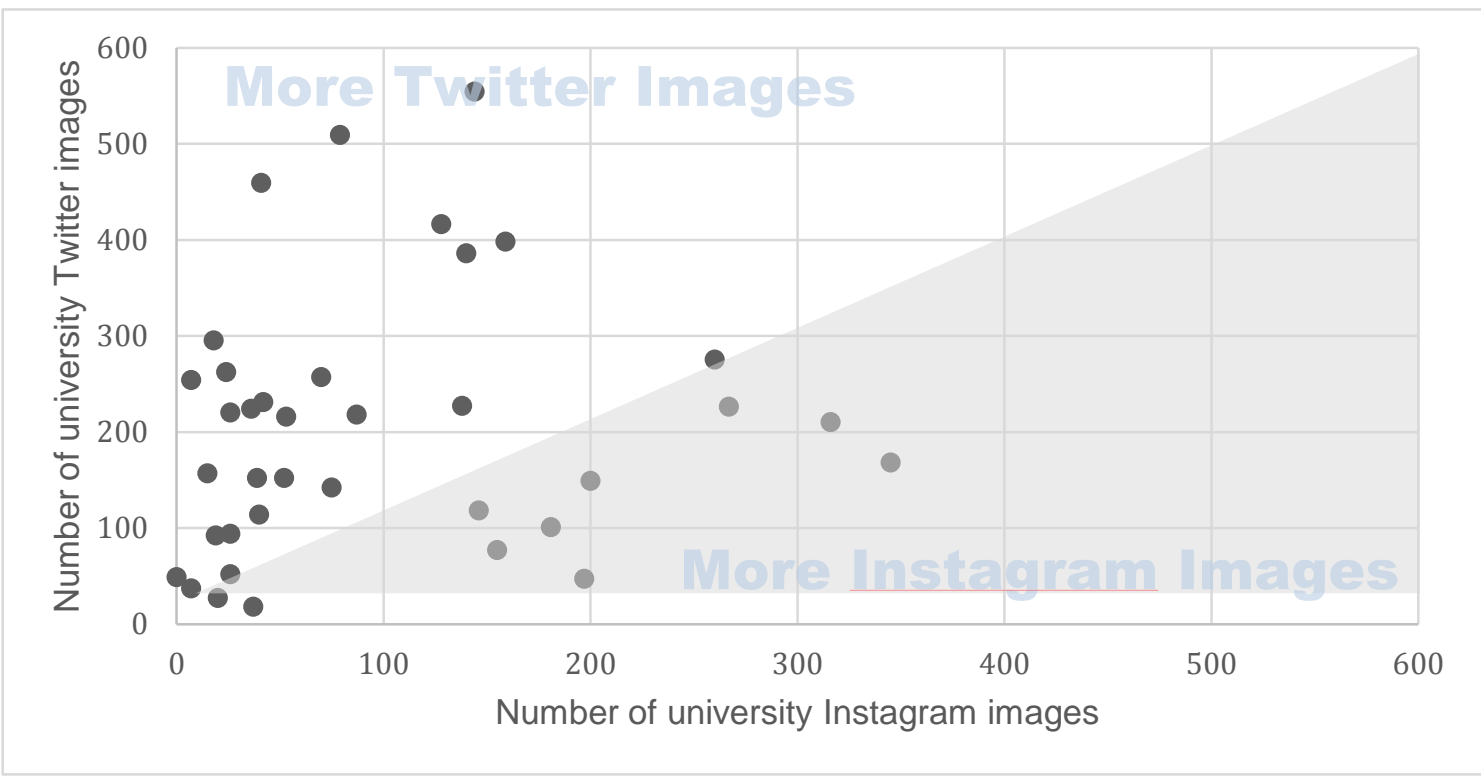

\section{Figure 2. Number of images posted to Twitter and Instagram by 51 UK universities.}

\section{Discussion}


The popularity of showcasing images for UK universities on Twitter fits with the common use of Twitter as an information source rather than for social networking (Kwak et al., 2010; Chung and Yoon, 2013). More specifically, it agrees to some extent with the predominant use of Twitter by academic institutions for one-way communication with current students (Davis III et al., 2012), although showcasing images are presumably more aimed at prospective students. Showcasing images promote/display/report/publicize university products/events/services, and this type of image could perhaps be described as 'sharing information' (Java et al., 2007; Naaman et al., 2010). However, as shown by the showcasing images in Figure 1, it is often the text of the tweet that is sharing the information, and the images are merely there to accompany the text, or to 'illustrate' it (Chung and Yoon, 2013). The first image shown in Figure 1 is a photograph of a university campus, accompanying a tweet about an upcoming open day. Similarly, the second image in Figure 1 relates to the subject matter of an upcoming public talk at the university. In these two examples, the text of the tweets shares the main information, with the images not particularly containing any extra details. Since incorporating images with tweets fosters engagement and boost retweets (Rogers, 2014), the purpose here is presumably to get the messages noticed. The third Figure 1 example includes the key information as text within the graphically designed image as well as through a hyperlink in the tweet: that the university management school had maintained its top position in a league table. In this case the 
image does not need the accompanying tweet text to give context to the image but only because the text within the image contains the information.

In this investigation, no analysis was made of the areplies to any of the image posts investigated, and it is therefore possible that showcasing images generated many reactions from followers, thus positioning the images more as social networking tools than information sources. However, regardless of the interaction generated from a post, if the original intention behind the post was to broadcast specific information then this supports the claims that Twitter is used more to share information than to build networks. The numerical difference between the most popular type of image (showcasing: 61 percent) and the second most popular type (humanizing: 21 percent), suggests that Twitter is mainly used to broadcast university-specific information, with the images only providing a visual accompaniment to the text.

The results differ greatly from those for Instagram from the same set of universities since humanizing images were the most popular type of image on Instagram (Stuart et al., 2017). This reflects the differences between Instagram and Twitter. Instagram is a mobile-only image sharing service, and images are the central focus of all Instagram posts. It offers an 'all-in-one package' (Lee et al., 2015), which enables users to take photos from within the app itself, edit photos, transform them via filters, and upload and share them with other Instagram followers. These 
filters often give images a dreamy and romantic feel and this is so common that the tag \#nofilter is used to label those images that are unmodified (Marwick, 2015). Within Instagram, images that are aesthetically pleasing are highly regarded and it is common practice to be selective about image posting, with only a few posts each day (Marwick, 2015). These two factors may drive the posting of images that have a human character and warmth (i.e., humanizing images) •

The dominance of showcasing images on Twitter suggests that it is clearly established as an 'information broadcasting' channel, in contrast to the wider range of typical uses for Instagram. This aligns with earlier work by Small (2011) who found that information sharing was the main driver for users tweeting about Canadian politics on Twitter. It also fits with Bergie and Hodson's (2015) findings that discussion on Twitter is driven by traditional media organisations and that the general user base merely act as an echo chamber for what has already been said, 'reiterating the message of those in power' (p. 262).

The extra retweeting found for showcasing images in comparison to humanizing images on Twitter suggests that they are successfully performing their role of disseminating information. Showcasing images aim to promote/display/report/publicize university products/events/services, suggesting that retweeting reflects users believing that the information contained within the tweet is 
useful (e.g., the time and location of a lecture, freshers' fayre or graduation ball).

The universities posted more images to Twitter $(7,583)$ than Instagram $(3,615)$ over the same time period. However, this difference is likely to be due to several reasons. First, as mentioned above, it is common practice on Instagram to be selective, with a maximum of two images per day being posted (Marwick, 2015). This is likely to be the main reason as to why more images are posted to Twitter by UK universities. Second, whereas Instagram users can only edit and upload images to Instagram via their mobile phones, Twitter is also web-based, which makes it easier for multiple staff within a university to access the University Twitter account and post content. Organizations can ghostwrite Twitter with different people posting content accompanied by stock images or images re-appropriated from other sources. Instagram's mobile-based access is likely to further limit the frequency with which images are posted. Third, Instagram is a newer service (Twitter was launched in 2006, and Instagram in 2010). It can take time for an organization to develop a coherent usage policy for each new social media service, and they may adopt a conservative strategy and post minimally until new services are better understood. Lastly, retweets are very popular on Twitter and many people's timelines are populated with retweeted information. The mechanism for retweeting is a single click. In contrast, a separate repost app is needed to regram on Instagram. Moreover, personally created images are 
important within Instagram and so regrams are not a natural feature.

Although UK universities posted more images to Twitter than Instagram, it should not be inferred that Twitter is better for university images. As outlined above, images can be secondary in Tweets and slow posting on Instagram may be a deliberate policy to match users' expectations.

\section{Conclusions}

This research has several limitations. Most importantly, it covers only one country and only includes universities with an Instagram profile. Another limitation is that the content analysis analyses each image and tweet separately rather than positioning it within the social media campaign of the originating university. It is therefore possible that the images perform functions other than the ones identified here.

The results reveal substantial differences between the image posting practices of UK universities on Twitter and Instagram. Although UK universities tend to post self-contained humanizing images to Instagram, the same set of 51 UK universities mainly posted showcasing images on Twitter to support textual messages, and also tweeted twice as many images in total. Showcasing images promote/display/report/publicize university products/events/services, suggesting that Twitter is an information-sharing network for current and prospective students. 
Images tended to illustrate the accompanying tweet text or to contain embedded text, rather than being purely visual. They were also more likely to be re-appropriated from other sources (e.g., phone screen shots, pictures of text messages, stock photos, graphic images etc.) rather than originating as a smartphone photograph, as is predominantly the case with Instagram. University communication departments should recognise that the two services perform different functions and should therefore have separate communication strategies for each one.

Because the use of showcasing images was dominant for UK universities on Twitter (61 percent of images), it would be useful for staff members who are responsible for the online communication strategy of a particular university to post more images of different types (i.e., orienting, humanizing, interacting, placemaking, and crowdsourcing) in order to try to connect with followers in new and more innovative ways, rather than merely using it as an information sharing service. This strategy could be aligned with the practice of content curation, whereby the staff member(s) in charge of the Twitter account would specifically attempt to highlight a range of interesting and meaningful content that they think would appeal to their followers (Zhong et al., $2013)$.

In terms of future research, it would be useful to explore the interactions between university accounts and their followers to determine if different types of images generate more @replies, and 
whether these replies discuss the original post. It would also be interesting to conduct a content analysis that compares the types of image formats posted to Twitter and Instagram (e.g., photographs, phone screen shots, pictures of text messages, graphic images) to explore more deeply the differences between the two services. This investigation has highlighted that Twitter images tend to be accompaniments to the text contained within a tweet and may be stock photographs from the university marketing department, or graphically created images sharing information. It would also be useful to assess the strategies of universities in other countries and other social media services.

\section{References}

Angus, E. and Thelwall, M. (2010), "Motivations for image publishing and tagging on Flickr", in Turid Hedlund and Yasar Tonta (Eds.), in Proceedings of the 14th International Conference on Electronic Publishing, Hanken School of Economics, Helsinki, pp. $189-204$

Bélanger, C.H., Bali, S. and Longden, B. (2014). "How Canadian universities use social media to brand themselves", Tertiary Education and Management, Vol. 20 No. 1, pp. 14-29.

Bélanger, C., Mount, J. and Wilson, M. (2002). "Institutional image and retention", Tertiary Education \& Management, Vol. 8 No. 3, pp. 217-230. 
Bennett, S. (2013), "36\% of all links shared on Twitter are images", Adweek, available at:

http://www.adweek.com/digital/twitter-images/, accessed 26 June 2017

Bergie, B. and Hodson, J. (2015). "The Twitter citizen:

Problematizing traditional media dominance in an online political discussion", in Nathan Rambukkana (ed.) Hashtag publics: The power and politics of discursive networks, Peter Lang, pp. 255-265.

Bilton, N. (2012), "Twitter loses ability to properly display Instagram photos", Bits Blog, New York Times, 5 December, available at: http://bits.blogs.nytimes.com/2012/12/05/twitterloses-ability-to-properly-display-instagram-photos/, accessed 22 March 2016.

Bourlai, E. and Herring, S.C. (2014), "Multimodal communication on Tumblr: 'I have so many feels!'", in Proceedings of the 2014 ACM conference on Web science, ACM, pp. 171-175.

Burkhardt, A. (2010), "Social media: A guide for college and university libraries", College \& Research Libraries News, Vol. 71 No. 1, pp. 10-24.

Calore, M. (2013), "Embed Instagram photos in your Twitter feed with this workaround", Wired, 10 January, 2013, available at: 
http://www.wired.com/2013/10/how-to-twitter-instagram/, accessed 22 April 2016.

Chang, H.C. (2010), "A new perspective on Twitter hashtag use: Diffusion of innovation theory", in Proceedings of the American Society for Information Science and Technology, Vol. 47 No. 1, $\mathrm{pp} \cdot 1-4$

Chung, E. and Yoon, J. (2013), "An analysis of image use in Twitter message", Journal of the Korean Biblia Society for Library and Information Science, Vol. 24 No. 4, pp. 75-90.

Coelho, R.L.F., Oliveira, D.S.D., and Almeida, M.I.S.D. (2016), "Does social media matter for post typology? Impact of post content on Facebook and Instagram metrics", Online Information Review, Vol. 40 No. 4, pp. 458-471.

Conole, G. and Alevizou, P. (2010), "A literature review of the use of Web 2.0 tools in Higher Education", A report commissioned by the Higher Education Academy.

Constantinides, E., and Zinck Stagno, M. C. (2011), "Potential of the social media as instruments of higher education marketing: A segmentation study", Journal of Marketing for Higher Education, Vol. 21, pp. 7-24. doi: 10.1080/08841241.2011.573593 
Dahlstrom, E., Walker, J. D. and Dziuban, C. (2013). "ECAR study of undergraduate students and information technology", 2013. Louisville, CO: EDUCAUSE Center for Analysis and Research.

Dancey, C. P. and Reidy, J. (2004), Statistics without maths for psychology, Pearson Education Limited, Essex, England.

Davis III, C.H., Deil-Amen, R., Rios-Aguilar, C. and Gonzalez Canche, M.S. (2012), "Social media in higher education: A literature review and research directions", Report printed by the University of Arizona and Claremont Graduate University, 8.

Duarte, P.O., Alves, H.B. and Raposo, M.B. (2010). "Understanding university image: a structural equation model approach". International Review on Public and Nonprofit Marketing, Vol. 7 No. $1, \mathrm{pp} \cdot 21-36$

Graham, M. E. (2001), "The cataloguing and indexing of images: Time for a new paradigm?", Art Libraries Journal, Vol. 26 No. 1, pp. $22-27$

Gruzd, A. Haythornthwaite, C., Paulin, D., Gilbert, S., and del Valle, M. E. (2016), "Uses and Gratifications factors for social media use in teaching: Instructors' perspectives," New Media and Society, Aug. 2016. doi:10.1177/1461444816662933

Gruzd, A., Paulin, D., and Haythornthwaite, C. (2016), "Analyzing 
Social Media and Learning through Content and Social Network Analysis: A Faceted Methodological Approach", Journal of Learning Analytics, Vol. 3 No. 3, pp. 46-71.

Hansen, K. Nowlan, G. and Winter, C. (2012), "Pinterest as a tool: applications in academic libraries and higher education", Partnership: The Canadian journal of library and information practice and research, Vol. 7 No. 2., available at:

http://davinci.lib.uoguelph.ca/index.php/perj/article/view/2011/26 31\#.Wcq9t4VcByQ, accessed 15 January 2016.

Hochman, N. (2014), "The social media image", Big Data \& Society, Vol. 1 No. 2, DOI: 10.1177/2053951714546645.

Honeycutt, H. and Herring, S.C. (2009), "Beyond microblogging: Conversation and collaboration via Twitter", in 42nd Hawaii International Conference on System Sciences, Waikoloa, Big Island, Hawaii, IEEE Computer Society Washington, DC, USA, pp. 1-10.

Java, A., Song, X., Finin, T. and Tseng, B. (2007), "Why we twitter: Understanding microblogging usage and communities", in Proceedings of the 9th WebKDD and 1st SNA-KDD 2007 workshop on Web mining and social network analysis, ACM Press, New York, pp. 5665 .

Jenkins, N. (1991). The business of image: Visualising the corp message, Kogan Page Limited, London. 
Kim, D.H., Spiller, L. and Hettche, M. (2015), "Analyzing media types and content orientations in Facebook for global brands", Journal of Research in Interactive Marketing, Vol. 9 No. 1, pp. 430 .

Kittle, B. and Ciba, D. (1999), "Relationship marketing in higher education via the World Wide Web: a study of home pages examining student retention strategies", in Proceedings of the 1998 Symposium for the Marketing of Higher Education, American Marketing Association, Chicago, pp. 165-175.

Krippendorf, K. (2004), Content Analysis: An Introduction to its Methodology, Sage Publications, USA.

Kwak, H., Lee, C., Park, H. and Moon, S. (2010), "What is Twitter, a social network or a news media?", in Proceedings of the 19th international conference on World wide web, ACM, pp. 591-600.

Lee, D. (2016), "Instagram users top 500 million", BBC News, Technology, 21 June, available at:

http://www.bbc.co.uk/news/technology-36584511, accessed 21 June 2016.

Lee, E., Lee, J.A., Moon, J.H. and Sung, Y. (2015), "Pictures Speak Louder than Words: Motivations for Using Instagram", 
Cyberpsychology, Behavior, and Social Networking, Vol. 18 No. 9, pp. $552-556$

Linvill, D. L., McGee, S. E., \& Hicks, L. K. (2012), "Colleges' and universities' use of Twitter: A content analysis", Public Relations Review, Vol. 38, pp. 636-638. doi:

$10.1016 / j \cdot$ pubrev.2012.05.010

Marwick, A.E. (2015), "Instafame: Luxury selfies in the attention economy", Public Culture, Vol. 27 No. 1 75, pp.137-160.

McFedries, P. (2007), "Technically Speaking: All A-Twitter", IEEE Spectrum, Vol. 44 No. 10, p. 84.

McNely, B. (2012), "Shaping organizational image-power through images: Case histories of Instagram", Proceedings of the IEEE International Professional Communication Conference, IEEE, Piscataway, NJ.

Moore, C. (2014), "Screenshots as virtual photography: Cybernetics, remediation and affect", in P. Arthur \& K. Bode (Eds.) Advancing digital humanities research, methods, theories, Palgrave Macmillan, London, pp. 258-273.

Moran, M., Seaman, J. and Tinti-Kane, H. (2011), "Teaching, learning, and sharing: How today's higher education faculty use social media", Babson Survey Research Group, available 
at: http://files.eric.ed.gov/fulltext/ED535130.pdf, accessed 19 July 2015 .

Murthy, D. (2011), "Twitter: Microphone for the masses?", Media Culture and Society, Vol. 33 No. 5, p.779-789.

Naaman, M., Boase, J. and Lai, C.H. (2010), "Is it really about me?: message content in social awareness streams", in Proceedings of the 2010 ACM conference on Computer supported cooperative work, ACM, pp. 189-192.

OMNICORE. (2017). "Twitter by the Numbers:

stats, demographics \& fun facts", January 24, available at: https://www.omnicoreagency.com/twitter-statistics/

Opoku, R., Abratt, R. and Pitt, L. (2006). "Communicating brand personality: are the websites doing the talking for the top South African business schools?", Journal of Brand Management, Vol. 14 No. 1-2, pp. 20-39.

O'Reilly, L. (2014), "Now Instagram is dominating Twitter in another hugely important way", 17 December, Business Insider, available at: http://uk.businessinsider.com/instagram-engagementrates-up-to-50-times-higher-than-twitter-socialbakers-finds-201412?r=US\&IR=T, accessed 22 April 2016. 
Parr, C. (2014), "Top 100 most influential UK and US universities on Twitter", Times Higher Education, available at:

https://www.timeshighereducation.co.uk/news/top-100-mostinfluential-uk-and-us-universities-on-twitter/2013373.article, accessed 19 July 2015.

Peranginangin, Y. and Alamsyah, A. (2015), "Social engagement analysis in online conversation of Indonesia higher education: Case study: Telkom university", Proceedings of the $3^{\text {rd }}$ International Conference on Information and Communication Technology (ICOICT), (pp. 228-233). IEEE.

Rauschnabel, P.A., Praxmarer, S. and Ivens, B.S. (2012). "Social media marketing: How design features influence interactions with brand postings on Facebook", In Advances in Advertising Research (Vol. III) (pp. 153-161). Gabler Verlag.

Reuben, R. (2008), The use of social media in higher education for marketing and communications: A guide for professionals in higher education.

Rogers, S. (2014), "What fuels a Tweet's engagement?", 10 March, available at: https://blog.twitter.com/2014/what-fuels-a-tweetsengagement, accessed 23 March 2016.

Rolfe, H. (2003), "University strategy in an age of uncertainty: the effect of higher education funding on old and new 
universities", Higher Education Quarterly, Vol. 57 No. 1, pp. 2447.

Rose, G. (2016), Visual methodologies: An introduction to researching with visual materials. Sage.

Rosen, A. (2017), "Tweeting made easier", Twitter Blog, 7 November, available at:

https://blog.twitter.com/official/en_us/topics/product/2017/tweeti ngmadeeasier.html, accessed 12 september 2018.

Salomon, D. (2013), "Moving on from Facebook: Using Instagram to connect with undergraduates and engage in teaching and learning", College \& Research Libraries News, Vol. 74 No. 8, pp. 408-412.

Small, T. A. (2011). What the hashtag? Information, Communication \& Society, Vol. 14 No. 6, pp. 872-895. Retrieved from http://doi.org/10.1080/1369118x.2011.554572

Statista (2018), "Distribution of Twitter users in the United Kingdom (UK) from 2012 to 2018, by age group", Statista, available at:

https://www.statista.com/statistics/271351/twitter-users-in-theunited-kingdom-uk-by-age/, accessed 18 February 2018.

Statista (2019), "Leading countries based on number of Twitter users as of January 2019 (in millions)", Statista, available at: 
https://www.statista.com/statistics/242606/number-of-activetwitter-users-in-selected-countries/, accessed 18 February 2019.

Stuart, E., Stuart, D. and Thelwall, M. (2017), "An investigation of the online presence of UK universities on Instagram", Online Information Review, Vol. 41 No. 5, pp. 582-597.

Selwyn, N. (2012), "Social media in higher education", The Europa world of learning, pp. 1-10.

Shao, C., Ciampaglia, G.L., Flammini, A. and Menczer, F. (2016), "Hoaxy: A platform for tracking online misinformation", In Proceedings of the 25th international conference companion on world wide web, International World Wide Web Conferences Steering Committee, pp. 745-750.

Stamp, R. (2004), "The new challenge of branding buy-in", Education News, 7.

Swartzfager, B. (2007), "Twitter as Alert System?", available at: https://thoughtdelimited.blogspot.co.uk/2007/04/twitter-as-alertsystem.html, accessed 10 January 2018.

Taylor, C. (2011), "Twitter Unveils Photo \& Video Sharing", Mashable UK, 1 June, available at:

http://mashable.com/2011/06/01/twitter-photos/, accessed 23 March 2016. 
Tekulve, N. and Kelly, K. (2013), "Worth 1,000 words: Using Instagram to engage library users", Brick and Click Libraries Symposium, Roesch Library Faculty Publications, available at: http://ecommons.udayton.edu/cgi/viewcontent.cgi?article=1020\&conte xt=roesch fac, accessed 23 March 2016.

Thelwall, M. (2009), Introduction to Webometrics: Quantitative Web Research for the Social Sciences, Morgan \& Claypool, San Rafael, CA.

Thelwall, M., Goriunova, O., Vis, F., Faulkner, S., Burns, A., Aulich, J., Mas-Bleda, A., Stuart, E. and D'Orazio, F. (2016), "Chatting through pictures? A classification of images tweeted in one week in the UK and USA", Journal of the Association for Information Science and Technology, Vol. 67 No. 11, pp. 2575-2586.

Twitter Help Centre (no date). "Posting photos or GIFS on Twitter", available at:

https://support.twitter.com/articles/20156423\#, accessed 23 March 2016.

Westcott Alessandri, S. (2001), "Modeling corporate identity: a concept explication and theoretical explanation", Corporate Communications: An International Journal, Vol. 6 No. 4, pp. 173182. 
Yoon, J. and Chung, E. (2013), "How images are conversed on twitter?", Proceedings of the American Society for Information Science and Technology, Vol. 50 No. 1, pp. 1-5.

Zdanowicz, C. (2014), "'Miracle on the Hudson' Twitpic changed his life", CNN, 15 January, available at:

http://edition.cnn.com/2014/01/15/tech/hudson-landing-twitpickrums/index.html, accessed 16 May 2016.

Zhao, D. and Rosson, M. B. (2009), "How and why people Twitter: The role that micro-blogging plays in informal communication at work", in Proceedings of the ACM 2009 international conference on Supporting group work, ACM, pp. 243-252.

Zhong, C., Shah, S., Sundaravadivelan, K., and Sastry, N. (2013), "Sharing the Loves: Understanding the How and Why of Online Content Curation", in Proceedings of the 7th International AAAI Conference on Weblogs and Social Media, (ICWSM), 2 - 4 June. 